ORIENTAL JOURNAL OF CHEMISTRY

An International Open Free Access, Peer Reviewed Research Journal

www.orientjchem.org
ISSN: 0970-020 X

CODEN: OJCHEG

2017, Vol. 33, No.(5):

Pg. 2257-2262

\title{
Liquid Biofuel Production from Palm Oil Using Dual-Function of Zn/HZSM-5 Catalyst
}

\section{PAKPOOM SANGDARA, MALIWAN SUBSADSANA and CHALERM RUANGVIRIYACHAI*}

\author{
Materials Chemistry Research Center, Department of Chemistry and Center of Excellence for \\ Innovation in Chemistry, Faculty of Science, Khon Kaen University, Khon Kaen,Thailand. \\ ${ }^{*}$ Corresponding author E-mail: chal_ru@kku.ac.th
}

http://dx.doi.org/10.13005/ojc/330513

(Received: April 04, 2017; Accepted: July 20, 2017)

\begin{abstract}
To produce high yield and quality hydrocarbon biofuel, HZSM- 5 zeolite loaded with different Zn concentrations (5, 10, 15 and $20 \mathrm{wt} . \%)$ was used to palm oil cracking in batch reactor. Reaction temperature and reaction time were optimized. The products contained liquid hydrocarbon biofuel, distillation residual and coke. The physical properties of biofuel products were determined. The results presented that $15 \% \mathrm{Zn} / \mathrm{HZSM}-5$ exhibited higher hydrocarbon biofuel yield $(20.27 \%)$ and their excellent product properties with higher heating value $(\mathrm{HHV})$, low viscosity and moisture content. A highest hydrocarbon biofuel yield and good alkane range hydrocarbons distribution from palm oil were obtained under reaction temperature of $420^{\circ} \mathrm{C}$ for 5 hours.
\end{abstract}

Keywords: Alkanes, Catalyst, Hydrocarbon biofuel, Palm oil cracking, Zn/HZSM-5.

\section{INTRODUCTION}

Due to an increase in energy demand and lacking of world's energy resource, the developments of renewable energies have attracted a great interest. The biomass conversion technology is one of the wonderful candidates to resolve the problem of an insufficient energy. In modern science, the production of green fuels has been focused on vegetable oils as raw renewable fats. Generally, trans-esterification method was used for producing of biofuel from the oils ${ }^{1}$. However, the biofuel production from transesterification is lower oxidative and ambient stability. In order to solve this issue, a catalytic hydro-treatment and cracking processes have been developed to produce green biofuel from vegetable oils. The advantage of this biofuel has low greenhouse gas and toxic components such as nitrogen and sulfur compounds. The hydrotreatment products were obtained from hydrogenation by acid function of catalyst, which were greatly assisted to increase the products stability due to an increasing of isomerization reaction ${ }^{2,3}$.

Recently, the variety of $\mathrm{Zn}$ loaded on NaZSM-5 catalyst was used for the production of liquid hydrocarbon from camelina oil ${ }^{4}$, but maximum yield of the liquid hydrocarbon was $19.56 \%$. And over $0.5 \%$ (w/w) of Zn added into ZSM5 catalyst provided a high yield aromatic 
hydrocarbon production from pyrolysis of Douglas fir sawdust pellets 5 . However, few researchers have done some progress on the liquid hydrocarbon biofuel production over Zn/HZSM-5 catalyst.

From this point of view, no study on $\mathrm{Zn}$ doped on HZSM- 5 catalyst for the cracking of palm oil has been reported. Therefore, the aim of this work is to produce a high hydrocarbon biofuel yields from the cracking of palm oil over $Z n$ doped on HZSM- 5 supports catalyst. Several affecting parameters such as concentration of zinc doped zeolite catalyst, reaction temperature and reaction time were investigated.

\section{EXPERIMENTAL}

Composition of palm oil was analyzed using Agilent GC-7890A. The HZSM-5 catalysts doped with different concentrations of $\mathrm{Zn}$ (5, 10, 15 and 20 wt.\%) were prepared using a wet impregnation method. The metal loading was carried out by adding a solution of zinc(II) nitrate hexahydrate to the zeolite in a rotary evaporator. After the impregnation, the catalysts were dried at $80^{\circ} \mathrm{C}$ for $2 \mathrm{~h}$ and then all catalysts were calcined at $500{ }^{\circ} \mathrm{C}$ under air for $3 \mathrm{~h}$. XRD pattern of catalysts were recorded on Rigaku RAD-C diffractometer with continuous scanned from $5^{\circ}-50^{\circ}(2 \theta)$. The surface area measurements and porous properties of the catalysts were analyzed using a QuantacrhomeAutsorb Analyzer.

The hydrocarbon biofuel production was carried out in 1000-ml batch reactor Amar Instrument (India) equipped with an automatic stirrer. In the experimental series, $300 \mathrm{ml}$ of palm oil and $10 \mathrm{~g}$ catalyst were loaded in the reactor chamber, sealed and filled with hydrogen to pressure of $3 \mathrm{MPa}$ under ambient temperature. The reaction was performed at $400^{\circ} \mathrm{C}$ for $3 \mathrm{~h}$. with stirring $500 \mathrm{rpm}$ over HZSM-5, 5\% Zn/HZSM-5, 10\% Zn/ HZSM-5, 15\% Zn/HZSM-5 and 20\% Zn/HZSM-5 catalysts. The upgraded palm oil was collected at ambient temperature and it was then distillated at $300^{\circ} \mathrm{C}$, which aimed to obtain the liquid biofuel based hydrocarbon. The main components of liquid biofuel via hydrocracking process were characterized by gas chromatography-mass spectrometry (GC-MS) and simulated distillation gas chromatography (Sim-Dis GC). The physicochemical properties of hydrocarbons biofuel such as high heating value (HHV), density, dynamic viscosity and moisture content were characterized. The HHV was evaluated based on ASTM D4809 using C2000 calorimeter system (IKAWork, Inc.). Density was examined by ratio of mass to volume of samples at ambient temperature. Dynamic viscosity was measured by using Viscosity Measuring Site VM 30150 (PSL systemtechnik). The moisture content was determined by using Karl Fischer instrument V10S Compact Volumetric KF Titrator.

\section{RESULTS AND DISCUSSION}

\section{Feedstock and catalyst characterization}

From the GC-MS analysis, the compositions of fatty acid from palm oil show palmetic acid $(40.65 \%)$, oleic acid $(37.87 \%)$, linoleic acid $(8.43 \%)$, stearic acid (5.69\%) and myristic acid (2.31\%). The XRD patterns of various $\mathrm{Zn}$ concentration catalyst supported on HZSM-5 are presented in Fig. 1. The XRD patterns of the fresh catalysts were similarity indicating that the framework of HZSM-5 was still kept after loading $\mathrm{Zn}$ (II). The $\mathrm{ZnO}$ phase was not observed for fresh catalysts suggesting that the metal oxide species were well dispersed on surface of the support HZSM- $5^{6,13}$. The BET surface areas and pore volumes of fresh catalysts are listed in Table 1 . The surface area and total pore volume of catalyst decreased when adding $\mathrm{Zn}$ to the HZSM-5 supports. This situation was due to pore blocking by metal oxide species dispersed in the channels of supports material ${ }^{7,14}$.

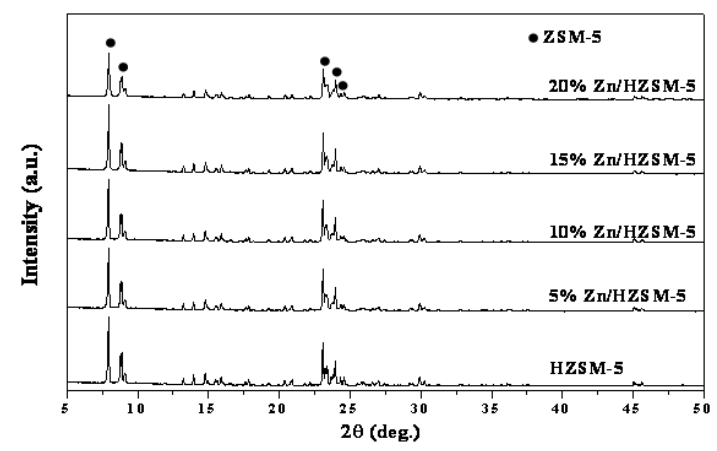

Fig. 1. XRD patterns of the catalysts 
Table. 1 : Surface area and porous properties of the catalysts used.

\begin{tabular}{lcccc}
\hline & & \multicolumn{3}{c}{ Pore volume $\left(\mathbf{c m}^{3} / \mathbf{g}\right)$} \\
\hline Catalysts & Surface area $\left(\mathrm{m}^{3} / \mathbf{g}\right)$ & Total & Micropores & Mesopores \\
\hline $\mathrm{HZSM}-5$ & 452.73 & 0.44 & 0.13 & 0.26 \\
$5 \% \mathrm{Zn} / \mathrm{HZSM}-5$ & 431.42 & 0.42 & 0.10 & 0.24 \\
$10 \% \mathrm{Zn} / \mathrm{HZSM}-5$ & 423.16 & 0.42 & 0.11 & 0.23 \\
$15 \% \mathrm{Zn} / \mathrm{HZSM}-5$ & 409.52 & 0.40 & 0.10 & 0.24 \\
$20 \% \mathrm{Zn} / \mathrm{HZSM}-5$ & 387.42 & 0.38 & 0.09 & 0.19 \\
\hline
\end{tabular}

\section{The effect of catalyst on product yield}

Figure 2 shows the yield of palm oil upgrading product that includes hydrocarbon biofuel, distillation residual and coke. The mass of coke was determined by difference weight of reactor before and after the cracking. The hydrocarbon biofuel yield increases with increased concentration of zinc. The increase in $\mathrm{ZnO}$ concentration to the HZSM-5 supports could enhance the yield of hydrocarbon biofuel due to the increase of Lewis acid site, which will do transform fatty acid to hydrocarbon based biofuels ${ }^{6}$. The yield of hydrocarbon biofuel over $20 \%$ $\mathrm{Zn} / \mathrm{HZSM}-5$ catalyst decreased, which this might be indicated that the aggregation of $\mathrm{ZnO}$ particles. The aggregation of $\mathrm{ZnO}$ that results from decreasing micropores and mesopores volume of the catalyst (see in Table 1) leading to pores blocking and reduce the active sites of catalyst. The distillation residual yields of $\mathrm{Zn}$ loaded to HZSM-5 supports were higher than that $\mathrm{HZSM}-5$ without $\mathrm{Zn}$. This fact results in acid site on the catalysts promoted the chemical reaction such as cracking and deoxygenation during palm oil cracking led to conversion of triglyceride molecules to hydrocarbon based biofuel ${ }^{16}$. The coke yield produced with zinc loaded HZSM-5 catalysts was higher than that HZSM-5 without zinc load catalyst. This fact might be due to that the metals loaded HSZM-5 with high activity of producing aromatic hydrocarbon and polymerized to form coke ${ }^{8}$.

\section{The effect of catalyst on physical properties of liquid hydrocarbon product}

Table 2 shows the physical properties of hydrocarbon biofuel produced without and with $\mathrm{Zn}$ loaded catalyst. Hydrocarbon biofuel had much lower viscosity than that of raw palm oil. The reason is that some large and complicated palm oil molecules had been cracked into smaller and simpler molecules. However, there was no significant difference between the viscosities of all hydrocarbon biofuels produced without and with $\mathrm{Zn}$ loaded catalyst. After the palm oil upgrading, the density of all hydrocarbon biofuels decreased to $0.76-0.84 \mathrm{~g} / \mathrm{ml}$, which was lower than the density raw palm oil. During the upgrading process, palm oil triglyceride molecules were decomposed to fatty acids that then underwent chemical reactions such as deoxidation and decarboxylation to form hydrocarbons and/or alcohols ${ }^{9}$. In this study, there was obvious water phase separated from the oil phase while collecting liquid oil, although some chemical reactions such as dehydration could produce water during the cracking of palm oil. The water content of hydrocarbon biofuel produced with $\mathrm{Zn}$ loaded catalyst was lower than that of hydrocarbon biofuel produced without $\mathrm{Zn}$ loaded catalyst. This indicates that the use of zinc loaded HZSM-5 inhibited the dehydration during the palm oil cracking process, which led to the lower water content of the hydrocarbon biofuel. The HHVs of all hydrocarbon biofuels increased after upgrading, compared to raw palm oil. During the palm oil upgrading, oxygen atoms were removed through the reactions such as deoxidation, decarboxylation, decarbonylation and dehydration, which led to the increase of HHV. One possible reason is that the water content of hydrocarbon biofuel produced without $\mathrm{Zn}$ loaded catalyst was higher than that of hydrocarbon biofuel produced with $\mathrm{Zn}$ loaded catalyst, as shown in Table 2. The higher water content would result in the lower HHV of the hydrocarbon biofuel ${ }^{9,15}$. As mentioned above, the $15 \% \mathrm{Zn} / \mathrm{HZSM}-5$ catalyst evidently presented the highest hydrocarbon biofuel yield and excellent 
properties of biofuel products. Therefore, this catalyst was selected as a catalyst in the following experiments to produce high hydrocarbon biofuel yield.

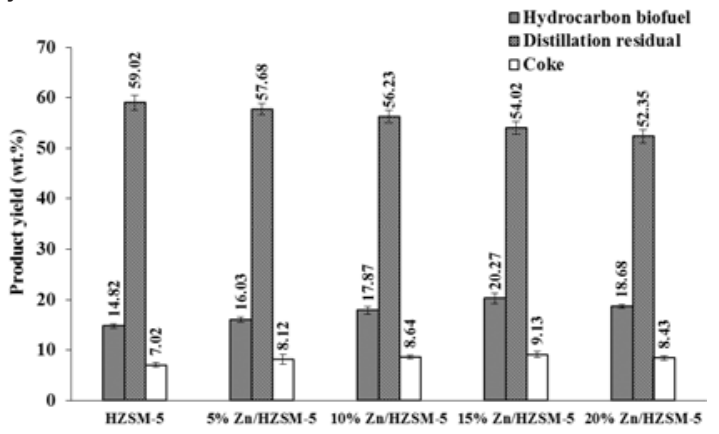

Fig. 2. The product yield of palm oil upgrading over different catalysts. different carbon numbers is shown in Figure 4. At $360^{\circ} \mathrm{C}$, tetradecane $(\mathrm{C} 14)$ and pentadecane $(\mathrm{C} 15)$ presented higher selectivity than the other hydrocarbons. In contrast, the short chain hydrocarbons (C6-C12) presented higher selectivity than long chain hydrocarbons (C13-C15), when using the reaction temperature of $440^{\circ} \mathrm{C}$. This result illustrated that transformation of heavy hydrocarbons into lighter hydrocarbons by severe cracking. At 380,400 and $420^{\circ} \mathrm{C}$, the selectivity of alkane range hydrocarbons with different carbon numbers increased with reaction temperature. The high hydrocarbon biofuel yield and a good alkane distribution were observed at $420^{\circ} \mathrm{C}$.

Table. 2: Physical properties of liquid hydrocarbon biofuel.

\begin{tabular}{|c|c|c|c|c|}
\hline Treatment & HHV (MJ/kg) & Viscosity (cP) & Density $(\mathrm{g} / \mathrm{mL})$ & Moisture content (wt.\%) \\
\hline Raw palm oil & $38.83 \pm 0.01$ & $60.35 \pm 0.14$ & $0.91 \pm 0.02$ & $0.21 \pm 0.01$ \\
\hline HZSM-5 & $42.02 \pm 0.21$ & $1.06 \pm 0.02$ & $0.84 \pm 0.01$ & $0.14 \pm 0.01$ \\
\hline $5 \% \mathrm{Zn} / \mathrm{HZSM}-5$ & $42.32 \pm 0.32$ & $1.02 \pm 0.01$ & $0.82 \pm 0.02$ & $0.12 \pm 0.01$ \\
\hline $10 \% \mathrm{Zn} / \mathrm{HZSM}-5$ & $42.87 \pm 0.09$ & $1.00 \pm 0.01$ & $0.80 \pm 0.01$ & $0.11 \pm 0.02$ \\
\hline $15 \% \mathrm{Zn} / \mathrm{HZSM}-5$ & $43.08 \pm 0.11$ & $0.98 \pm 0.01$ & $0.76 \pm 0.01$ & $0.10 \pm 0.02$ \\
\hline $20 \% \mathrm{Zn} / \mathrm{HZSM}-5$ & $43.05 \pm 0.02$ & $0.95 \pm 0.02$ & $0.77 \pm 0.01$ & $0.10 \pm 0.03$ \\
\hline
\end{tabular}

\section{Effect of reaction temperature to yield and quality hydrocarbon biofuel}

Figure 3 presents the resulted of cracking reaction temperature over $15 \% \mathrm{Zn} / \mathrm{HZSM}-5$ catalyst to produce high yield and quality hydrocarbon biofuel with high composition of alkane. At $360^{\circ} \mathrm{C}$, low yield of liquid hydrocarbon biofuel and high distillation residual yield. This result indicates that the transformation of triglyceride to long chains fatty acid with dehydrogenation and dehydration. Yield of hydrocarbon biofuel further increased to 20.78 wt. $\%$ when increase the reaction temperature up to $420^{\circ} \mathrm{C}$. Increase in the reaction temperature that affected to enhance the activities of catalyst led to low distillation residual yield. At $440^{\circ} \mathrm{C}$, hydrocarbon biofuel and distillation residual yield decreased to 19.81 wt. $\%$ and 48.89 wt. $\%$ which was due to severe cracking reaction. Liquid hydrocarbons and triglycerides were cracked into gaseous products ${ }^{10}$. Another possible reason is the formation of coke from aromatic hydrocarbons through polymerization and aromatization that result in high coke yield ${ }^{8}$. The selectivity to alkane range hydrocarbons with

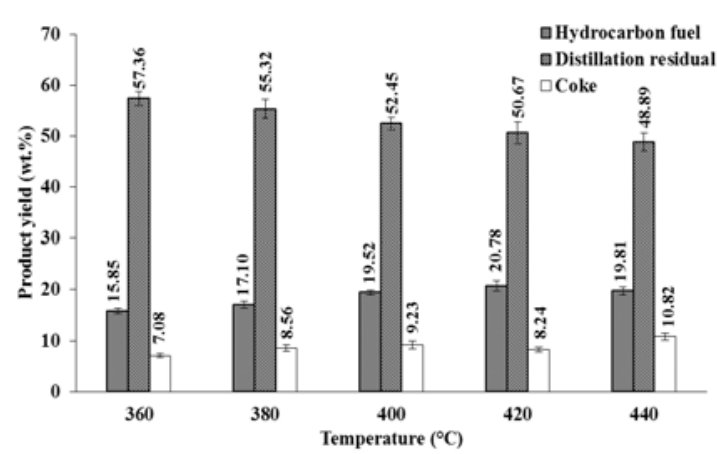

Fig. 3. The product yield of palm oil upgrading at different reaction temperatures

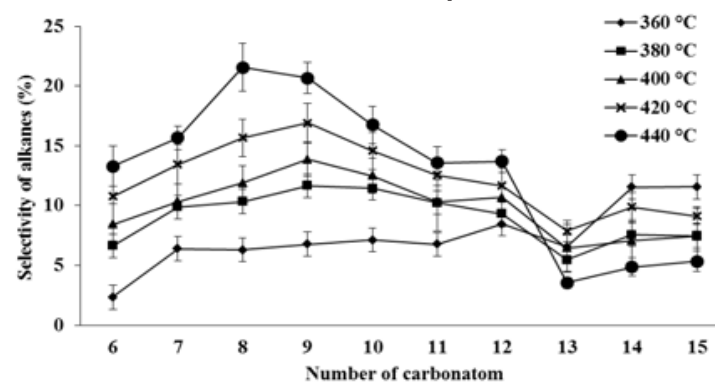

Fig. 4. The selectivity of alkanes with different carbon numbers over $15 \% \mathrm{Zn} / \mathrm{HZSM}-5$ 
Effect of reaction time to yield and quality hydrocarbon biofuel

Figure 5 shows the products yield during palm oil cracking over $15 \% \mathrm{Zn} / \mathrm{HZSM}-5$ catalyst at $420^{\circ} \mathrm{C}$ under various reaction times. At the first hour, low yield of hydrocarbon biofuel due to oligomerization occurred. Increased hydrocarbon biofuel yield from 14.58 wt.\% to 20.67 wt.\% with increasing reaction time from the first to the fourth hour. This phenomenon indicates that the remaining triglycerides and/or fatty acids further decomposition into hydrocarbons led to decreased distillation residual yield. From $4 \mathrm{~h}$ to $5 \mathrm{~h}$, the products trend was slightly changed might due to same cracking reaction pathway. In the $6 \mathrm{~h}$, the yields of hydrocarbon biofuel and distillation residual decreased as well. This result suggests that the

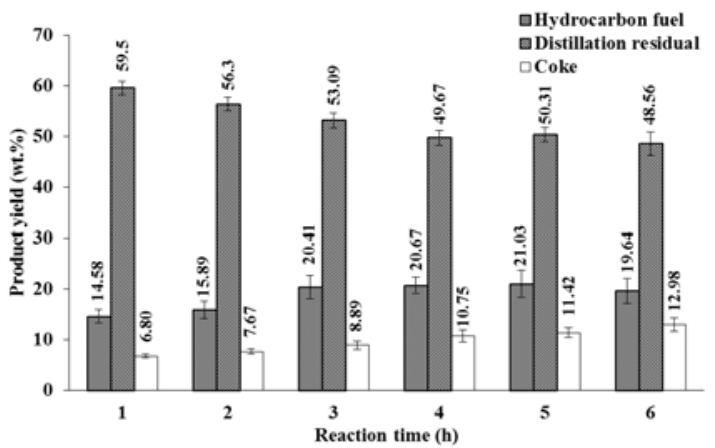

Fig. 5. The product yield of palm oil upgrading produced over $15 \% \mathrm{Zn} / \mathrm{HZSM}-5$ catalyst at different reaction times

\section{CONCLUSIONS}

The catalytic effects of HZSM-5 and Zn loaded HZSM-5 catalysts on the product yields and distribution were operated in the batch reactor system. The introduction of Zn on HZSM-5 catalyst was significantly increase yield and improve the properties hydrocarbon biofuel. The 15\% Zn/ HZSM- 5 catalyst exhibited a good ability to produce the highest amount of gasoline and high liquid hydrocarbon biofuel range alkane yield more than $20 \%$ from palm oil at $5 \mathrm{~h}$ under reaction temperature of $420^{\circ} \mathrm{C}$. formation of gas and aromatics, which then produced coke led to high coke yield. The selectivity to gasoline, kerosene and diesel with different carbon numbers of alkane is shown in Fig. 6. From $1 \mathrm{~h}$ to $2 \mathrm{~h}$, high selectivity to diesel due to hydrogenation and decabonylation of fatty acids ${ }^{11}$. In the third $\mathrm{h}$, the fatty acids and long chain hydrocarbons must be cracked into short chain hydrocarbons led to high selectivity to gasoline and kerosene. The kerosene was slightly changed with increased reaction time from $4 \mathrm{~h}$ to $6 \mathrm{~h}$. However, higher selectivity to gasoline than kerosene and diesel was observed when increased reaction time. This characteristic was due to severe cracking and influence of Lewis acid sites on catalyst promoted several reaction pathways to convert triglyceride and fatty acids into gasoline fraction ${ }^{12}$.

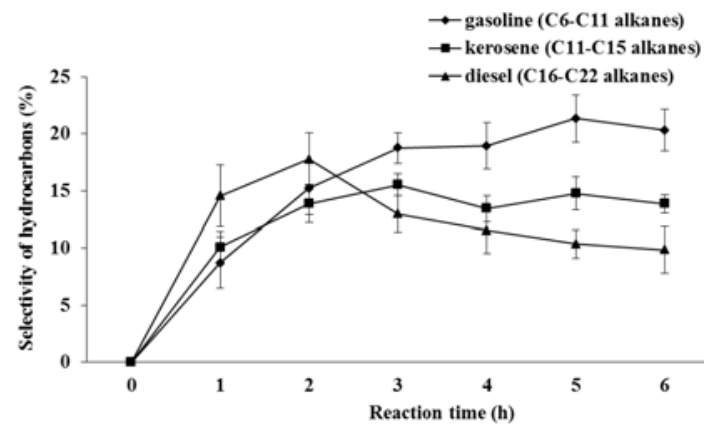

Fig. 6. Selectivity to gasoline, kerosene and diesel over $15 \% \mathrm{Zn} / \mathrm{HZSM}-5$ catalyst at various reaction times

\section{ACKNOWLEDGEMENTS}

This study was supported by National Research Council of Thailand, Materials Chemistry Research Center, Department of Chemistry and Center of Excellence for Innovation in Chemistry (PERCH - CIC), Faculty of Science, Khon Kaen University.

\section{REFERENCES}

1. Leung, D.Y.C.; Wu, X.; Leung, M.K.H. Appl Energ. 2010, 87(4),1083-1095.

2. Zhao, X.; Wei, L.; Julson, J.; Qiao, Q.; Dubey,
A.; Anderson, G. New Biotechnol. 2015, 32, 300-312.

3. Li, H.; Yu, P.; Shen, B. Fuel Process. Technol. 
2009, 90, 1087-1092

4. Zhao, X.; Wei, L.; Cheng, S.; Huang, Y.; Yu, Y.; Julson, J. Fuel Process. Technol. 2015, 139, 117-126.

5. Wang, L.; Lei, H.; Bu, Q.; Ren, S.; Wei, Y.; Zhu, L.; Zhang, X.; Liu, Y.; Yadavalli, G.; Lee, J.; Chen, S.; Tang, J. Fuel. 2014, 129, 78-85.

6. Ren, Y.; Zhang, F.; Hua, W.; Yue, Y.; Gao, Z. Catal. Today. 2009, 148(3-4), 316-322.

7. Khandan, N.; Mohammad, K.; Mahmoud, A.; Azadi, A. Iran. J.Chem. Eng. 2009, 6(1), 3-11.

8. Zhang, H.; Xiao, R.; Huang, H.; Xiao, G. Bioresour Technol. 2009, 108(3), 1428-1434.

9. Zhao, X.;Wei, L.; Julson, J.; Huang, Y. J. Sustainable Bioenergy Syst. 2014, 4, 199-214.
10. Ishihara, A.; Fukui, N.; Nasu, H.; Hashimoto, T. Fuel. 2014, 134, 611-617.

11. Li, T.; Cheng, J.; Huang, R.; Zhou, J.; Cen, K. Bioresour Technol. 2015, 197, 289-294.

12. Cheng, J.; Li, T.; Huang, R.; Zhou, J.; Cen, K. Bioresour Technol. 2014, 158, 378-382.

13. Subsadsana, M.; Ruangviriyachai, C. Orient J Chem. 2016, 32(2), 839-844.

14. Botas, J.A.; Serrano, D.P.; García, A.; de Vicente, J.; Ramos, R. Catal. Today. 2012, 195, 59-70.

15. Llamas, A.; Al-Lal, A.M.; Hernandez, M.; Lapuerta, M.; Canoira, L. Energy Fuels. 2012, 26, 5968-5976.

16. Subsadsana, M.; Sangdara, P.; Ruangviriyachai, C. Asia-Pac. J. Chem.Eng. 2017, 12, 147-158. 